\title{
ANALISIS KEPATUHAN PERAWAT PADA STANDAR ASUHAN KEPERAWATAN DI UNIT RAWAT INAP KELAS III RSU PKU MUHAMMADIYAH BANTUL YOGYAKARTA TAHUN 2010
}

\author{
Citra Ega Lestari, Rosyidah \\ Fakultas Kesehatan Masyarakat, Universitas Ahmad Dahlan, Yogyakarta
}

\begin{abstract}
Background: A hospital is an organization of health professionals through an organized and permanent medical facilities conducting medical services, continuous nursing care, diagnosis and treatment of illnesses suffered by patients. Nurses require documentation standards as guidance and direction in maintenance recording / documentation of activities and instructions for making patterns / recording formats appropriate, evidence recording and reporting on the status of the client and used as a communication tools that is accurate and complete. Nurses are not only required to improve the quality of nursing care, but also claimed to be properly documented. Nurses often do not obey and do the routine without regard to their legality aspect, although many factors are influence documentation. This study aims to determine compliance with standards of nursing care nurse at PKU Muhammadiyah Hospital in Bantul.

Methods: This was a qualitative descriptive research with a view to charging documents compliance with nursing standards of nursing care PKU Muhammadiyah Hospital in Bantul. This research was conducted with a view of nursing care standards document in May 2010. Implementation process that includes data collection, data processing, and presentation of comprehensive data and information accurately, timely, and trustworthy in the hospitalization.

Results: he results seen from the documentation of nursing care standards shows that the nurses in the inpatient unit class PKU Muhammadiyah Hospital in Bantul III comply with the standards of nursing care that is $100 \%$ obedient to categorize nurses in

assessment, diagnosis and planning, while $94.7 \%$ of nurses in the implementation of compliance and categorize $89.5 \%$ nurses in the evaluation categorize obedient.

Conclusion: Compliance with the standards of nursing care nurse in the Inpatient Unit

RSU PKU Muhammadiyah class III Bantul, has been running quite well because the nurse dutifully on the charging document nursing care standards.
\end{abstract}

Key words: compliance, standards of nursing care, nurse, in patient

\section{PENDAHULUAN}

Rumah sakit adalah institusi pelayanan kesehatan bagi masyarakat dengan karakteristik tersendiri yang dipengaruhi oleh perkembangan ilmu pengetahuan kesehatan, kemajuan teknologi, dan kehidupan sosial ekonomi masyarakat yang harus tetap mampu meningkatkan pelayanan yang lebih bermutu dan terjangkau oleh masyarakat agar terwujud derajat kesehatan yang setinggi-tingginya. ${ }^{1}$ Rumah sakit merupakan suatu organisasi yang melalui tenaga medis profesional yang terorganisir serta sarana kedokteran yang permanen menyelenggarakan pelayanan kedokteran, asuhan keperawatan yang berkesinambungan, diagnosis serta pengobatan penyakit yang diderita pasien. ${ }^{2}$

Menurut SK Menteri Kesehatan RI No. 983/Menkes/SK/XI/1992 menyebutkan bahwa rumah sakit umum adalah rumah sakit yang memberikan pelayanan kesehatan yang bersifat dasar, spesialistik, dan subspesialistik. Rumah sakit mempunyai misi memberikan pelayanan kesehatan yang bermutu dan terjangkau oleh masyarakat dalam rangka meningkatkan derajat kesehatan masyarakat. Tugasnya adalah melaksanakan upaya kesehatan secara berdayaguna dan berhasil guna 
dengan mengutamakan upaya penyembuhan dan pemulihan yang dilaksanakan secara serasi dan terpadu dengan upaya peningkatan dan pencegahan serta melaksanakan upaya rujukan. Untuk itu rumah sakit umum perlu mempunyai fungsi pelayanan medis, penunjang medis, pelayanan dan asuhan keperawatan, rujukan, pendidikan, pelatihan, penelitian, dan pengembangan serta menyelenggarakan administrasi umum dan keuangan. ${ }^{3}$

Pelayanan kesehatan yang bermutu adalah pelayanan kesehatan yang dapat memuaskan setiap pemakai jasa pelayanan sesuai dengan tingkat kepuasan ratarata penduduk, serta yang penyelenggaraannya sesuai dengan kode etik dan standar pelayanan yang telah ditetapkan. Asuhan keperawatan merupakan inti pelayanan/praktik keperawatan dalam upaya membantu mencapai kebutuhan dasar melalui bentuk tindakan keperawatan dengan menggunakan ilmu dan kiat keperawatan serta memanfaatkan potensi berbagai sumber. ${ }^{2}$

Asuhan keperawatan yang bermutu dan dapat dicapai jika pelaksanaan asuhan keperawatan dipersepsikan sebagai suatu kehormatan yang dimiliki oleh para perawat dalam memperlihatkan haknya untuk memberikan asuhan yang manusiawi, aman, serta sesuai dengan standar dan etika profesi keperawatan yang berkesinambungan dan terdiri dari kegiatan pengkajian, perencanaan, implementasi rencana, dan evaluasi tindakan keperawatan yang telah diberikan. ${ }^{4}$ Jumlah rumah sakit yang menerapkan pelayanan keperawatan sesuai standar dan pedoman sebanyak 160 rumah sakit di Indonesia. ${ }^{5}$

Rumah Sakit Umum PKU Muhammadiyah Bantul, sejak berdiri tahun 1966 dengan status Rumah Bersalin Khusus Ibu dan Anak (RB-KIA) sampai tahun 1995. Rumah Bersalin ini mempunyai ijin tetap pada tanggal 13 September 1976 berdasarkan Surat Keputusan Ka Kanwil DEPKES/ DINKES. Propinsi DIY (Tertanda dr. R. Soebroto, MPH) Nomor ijin Tetap : 14/ ldz/ T/ RB/ 76. Selanjutnya RS Khusus Ibu dan Anak berubah status menjadi Rumah Sakit Umum berdasarkan SK. Kepala Dinkes Kabupaten Bantul No.445 /4318 Tgl. 20 Oktober 2001. Pada tahun 2001 Rumah Sakit ini resmi menjadi rumah Sakit Umum tipe $C$ dengan jumlah tempat tidur sebanyak 104. Rumah sakit kelas C adalah rumah sakit yang mampu memberikan pelayanan kedokteran spesialis empat besar yaitu pelayanan spesialis ini yang disediakan yakni pelayanan penyakit dalam, pelayanan bedah, pelayanan kesehatan anak serta pelayanan kebidanan dan kandungan. ${ }^{2}$

Perawat memerlukan standar dokumentasi sebagai petunjuk dan arah dalam pemeliharaaan pencatatan/dokumentasi kegiatan serta petunjuk dalam membuat pola/format pencatatan tepat, bukti pencatatan dan pelaporan tentang status klien dan digunakan sebagai alat komunikasi yang akurat dan lengkap. Perawat tidak hanya dituntut untuk meningkatkan kualitas asuhan keperawatan tetapi juga dituntut untuk dapat mendokumentasikan secara benar. Seringkali perawat tidak patuh dan melakukan secara rutinitas tanpa memperhatikan aspek legalitasnya, walaupun banyak faktor yang menpengaruhi pendokumentasian. Oleh karena itu, dokumentasi keperawatan harus memenuhi standar yang telah ditentukan. Hasil observasi awal didapat bahwa Rumah Sakit PKU Muhammadiyah Bantul sudah mendapatkan ISO 9001:2000 untuk semua pelayanan kesehatan yang ada di rumah sakit PKU Muhammadiyah Bantul, termasuk juga pelayanan keperawatannya.

Berdasarkan hasil wawancara pada bagian diklat diketahui bahwa standar asuhan keperawatan sangat penting dilaksanakan terutama pada kepatuhan perawat pengisian dokumen standar asuhan keperawatan karena dengan dilaksanakannya pengisian tersebut akan dapat dilihat tingkat kepatuhan perawat terhadap standar asuhan keperawatan di RSU PKU Muhammadiyah Bantul dan juga dapat mempengaruhi pelayanan keperawatan yang baik. Pelayanan perawatan yang sesuai standar memiliki dampak yang lebih besar terhadap citra pelayanan rumah sakit.

KES MAS Vol. 5, No. 1, Januari $2011: 1$ - 67 
Kepatuhan adalah suatu perilaku manusia yang taat terhadap aturan, perintah, prosedur dan disiplin. Kepatuhan perawat adalah perilaku perawat sebagai seorang yang profesional terhadap suatu anjuran, prosedur atau peraturan yang harus dilakukan atau ditaati. Kepatuhan perawat dalam pendokumentasian asuhan keperawatan diartikan sebagai ketaatan untuk melaksanakan pendokumentasian asuhan keperawatan sesuai prosedur tetap yang telah ditetapkan. ${ }^{6}$

\section{METODE PENELITIAN}

Penelitian ini adalah penelitian deskriptif kualitatif. Penelitian ini menggunakan metode kualitatif yang bertujuan untuk membuat gambaran atau deskriptif tentang suatu keadaan secara objektif, digunakan dalam pelayanan kesehatan, terutama dalam rangka mengadakan perbaikan dan peningkatan program-program pelayanan kesehatan. Penelitian ini dilaksanakan di Rumah Sakit PKU Muhamadiyah Bantul. Waktu penelitian dilaksanakan pada 12 Juli - 6 Agustus 2010. Subjek penelitian ini adalah kepala ruangan rawat inap, dan enam orang perawat Rumah Sakit PKU Muhammadiyah Bantul. Variabel dalam penelitian ini menggunakan variabel tunggal yaitu kepatuhan perawat pada standar asuhan keperawatan di unit rawat inap kelas III Rumah Sakit PKU Muhammadiyah Bantul. Alat penelitian yang digunakan adalah panduan wawancara dan tape recorder.

\section{HASIL PENELITIAN DAN PEMBAHASAN}

\section{a. Hasil Penelitian}

Berdasarkan hasil penelitian dan informasi yang diperoleh dari bagian rawat inap kelas III Rumah Sakit PKU Muhammadiyah Bantul, maka dapat dideskripsikan tentang kepatuhan perawat pada standar asuhan keperawatan adalah sebagai berikut:

Tabel 1. Kategori Kepatuhan Perawat Pada Standar Asuhan Keperawatan di Ruang Rawat Inap Kelas III RSU PKU Muhammadiyah Bantul

\begin{tabular}{ccccc}
\hline \multirow{2}{*}{$\begin{array}{c}\text { Pelaksanaan Proses } \\
\text { Keperawatan }\end{array}$} & \multicolumn{2}{c}{ Patuh } & \multicolumn{2}{c}{ Tidak patuh } \\
\cline { 2 - 5 } & Frekuensi & Persentase & Frekuensi & Persentase \\
\hline Pengkajian & 76 & $100 \%$ & 0 & $0 \%$ \\
\hline Diagnosa & 76 & $100 \%$ & 0 & $0 \%$ \\
\hline Perencanaan & 76 & $100 \%$ & 0 & $0 \%$ \\
\hline Implementasi & 72 & $94.7 \%$ & 4 & $5,3 \%$ \\
\hline Evaluasi & 68 & $89,5 \%$ & 8 & $10,5 \%$ \\
\hline
\end{tabular}

Berdasarkan tabel kategori kepatuhan perawat pada Standar Asuhan Keperawatan pada tabel didapat bahwa:

a) Pelaksanaan pengkajian untuk mengumpulkan data dari pasien secara komprehensif $100 \%$ dikategorikan patuh.

b) Pelaksanaan perumusan diagnosis dari masalah-masalah keperawatan yang ditemukan pada saat pengkajian $100 \%$ perawat dikategorikan patuh.

c) Pelaksanaan perencanaan sesuai dengan diagnosis yang telah dibuat $100 \%$ perawat dikategorikan patuh.

Pelaksanaan tindakan keperawatan berdasarkan perencanaand $\quad$ a $n$ 
mengandung tujuan yang ingin dicapai $94,7 \%$ perawat dikategorikan patuh dan $5,3 \%$ perawat dikategorikan tidak patuh.

d) Pelaksanaan evaluasi tindakan keperawatan berdasarkan rencana dan kriteria yang telah ditetapkan $89,5 \%$ perawat dikategorikan patuh dan $10 \%$ perawat dikategorikan tidak patuh

Hasil analisis berdasarkan tabel dan perbandingan prosentase kepatuhan perawat pada standar asuhan keperawatan di unit rawai inap kelas III RSU PKU Muhammadiyah Bantul. Perawat patuh pada pelaksanaan pengkajian, diagnosis, pelaksanaan, implementasi dan evaluasi sesuai dengan standar asuhan keperawatan di ruang rawat inap kelas III RSU PKU Muhammadiyah Bantul. Keadaan ini menunjukkan perawat patuh pada standar asuhan keperawatan, ini sudah seharusnya berlaku di ruang rawat inap kelas III karena pelayanan yang diberikan oleh perawat sebagai pelayanan kesehatan yang profesional yang berkualitas.

\section{b. Pembahasan}

Berdasarkan hasil penelitian, perawat yang bekerja di Rumah Sakit PKU Muhammadiyah Bantul berlatar belakang pendidikan D3 Keperawatan. Pelatihan- pelatihan atau seminar untuk para perawat sudah pernah dilakukan di Rumah Sakit PKU Muhammadiyah Bantul. Pelatihan atau seminar tersebut dapat bermanfaat untuk melakukan evaluasi terhadap program-program dan standar-standar yang perlu perbaikan menurut kepala ruangan sedangkan untuk para perawat dapat menambah ilmu pengetahuan dan keperawatan, menambah wawasan dan pengalaman. Hasil observasi didapat bahwa, sumber daya manusia di RSU PKU Muhammadiyah Bantul masih kurang. Jumlah perawat dengan banyaknya kunjungan pasien rumah sakit tidak sebanding, sehingga menyebabkan pengisian dokumen standar asuhan keperawatan itu tidak lengkap karena banyaknya pasien. Kepatuhan perawat pada standar asuhan keperawatan

Rumah Sakit PKU Muhammadiyah Bantul belum mempunyai tim yang dapat memonitoring atau memantau kepatuhan perawat pada standar asuhan keperawatan tiap ruang inap, tapi bagian keperawatannya sudah ada dibagian ISO. Standar asuhan keperawatan harus terus ditinjau keakuratannya, sehingga tidak terjadi suatu kesalahan yang dapat merugikan pasien, selain itu perawat juga harus terus di bina untuk pencapaian kinerja yang profesional dan bertanggung jawab terhadap tugas-tugasnya. Standar keperawatan adalah pernyataan yang menggambarkan kualitas, karakteristik, sifat, kompentensi yang diinginkan dari beberapa aspek dalam proses keperawatan.

Pelatihan atau seminar dapat mengasah kemampuan para perawat untuk lebih baik. Hasil penelitian penyebab atau pun kendala perawat melaksanakan pengisian dokumen standar asuhan keperawatan adalah terbatasnya sumber daya manusia sehingga pekerjaan yang akan dilakukan begitu banyak dan kurangnya waktu untuk melakukan pengisian dokumen. Pengisian dokumen standar asuhan keperawatan merupakan tanggung jawab perawat. Perawat harus melaksanakan tugas-tugas yang dilimpahkan kepadanya, apabila terdapat kesalahan dalam pengisian akan dapat menimbulkan suatu masalah bagi pasien ataupun perawat itu sendiri dalam melaksanakan proses tindakan keperawatan. Kepatuhan perawat pada pengisian dokumen standar asuhan keperawatan dapat bermanfaat untuk melakukan tindakan yang terarah dan teratus sesuai dengan prosedur yang ada, dapat melakukan tindakan 
perkembangan pasien dan ada bukti pelaksanan tindakan keparawatan. Kelengkapan data merupakan suatu yang fakta, sesuai dengan keadaan pasian yang sebanarnya. Berdasarkan hasil wawancara dengan kepala ruangan, apabila terjadi suatu kesalahan akibat tidak patuhnya perawat dalam melakukan pengisian dokumen standar asuhan keperawatan yang harus dilakukan kepala ruangan yaitu:

1) Edukasi yaitu merupakan tanggung jawab kepala ruangan kepada perawat primer, mengapa hal itu terjadi.

2) SDM yaitu tanggung jawab perawat bagi setiap petugas, sistem penaggulangan jawaban.

\section{SIMPULAN DAN SARAN}

a. Simpulan

Berdasarkan hasil penelitian dan pembahasan dapat ditarik kesimpulan bahwa kepatuhan perawat pada standar asuhan keperawatan di unit rawat inap kelas III Rumah Sakit PKU Muhammadiyah Bantul dari data bulan 1 s/d 31 Mei 2010 yaitu :

1) Kepatuhan dari data dokumen standar asuhan keperawatan yaitu:

a) Pelaksanaan pengkajian untuk mengumpulkan data dari pasien secara komprehensif $100 \%$ dikategorikan patuh.

b) Pelaksanaan perumusan diagnosis dari masalah-masalah keperawatan yang ditemukan pada saat pengkajian $100 \%$ perawat dikategorikan patuh.

c) Pelaksanaan perencanaan sesuai dengan diagnosis yang telah dibuat $100 \%$ perawat dikategorikan patuh.

d) Pelaksanaan tindakan keperawatan berdasarkan perencanaan dan mengandung tujuan yang ingin dicapai $94,7 \%$ perawat dikategorikan patuh dan $5,3 \%$ perawat dikategorikan tidak patuh.

e) Pelaksanaan evaluasi tindakan keperawatan berdasarkan rencana dan kriteria yang telah ditetapkan $89,5 \%$ perawat dikategorikan patuh dan $10 \%$ perawat dikategorikan tidak patuh.

2) Kepatuhan perawat pada standar asuhan keperawatan.

a) Kepatuhan perawat pada standar asuhan keperawatan di unit rawat inap RSU PKU Muhammadiyah sudah cukup baik meski ada beberapa proses keperawatan yang tidak di isi dengan lengkap.

b) Penyebab atau kendala dalam pengisian dokumen standar asuhan keperawatan adalah terbatasnya sumber daya manusianya, dan kurang cukupnya waktu dalam mengisian dokumen.

c) Untuk memperbaiki masalah kepatuhan perawat pada standar asuhan keperawatan kepala ruangan melakukan dua hal yaitu Edukasi yaitu merupakan tanggung jawab kepala ruangan kepada perawat primer. Sumber daya manusia (SDM) yaitu tanggung jawab bagi setiap perawat, sistem penanggulangan jawaban.

\section{b. Saran}

1) RSU PKU Muhammadiyah Bantul

a) Agar dapat memperbaiki atau peningkatan kepatuhan perawat pada pendokumentasian standar asuhan keperawatan, dimana hasil evalusi masih banyak ditemukan catatan yang belum lengkap dalam pengisiannya, untuk itu diharapkan agar diadakan penyegaran kembali untuk perawat ruang tentang pendokumentasian standar asuhan keperawatan.

b) Pihak rumah sakit agar dapat membentuk tim untuk memantau 
kepatuhan perawat terutama dalam pengisian dokumen standar asuhan keperawatan.

2) Bagi kepala ruangan dan perawat inap

a) Agar kepala ruangan dapat melakukan tindakan untuk meningkatkan kepatuhan perawat dalam melaksanakan tugasnya dengan baik dalam pengisian dukumen standar asuhan keperawatan.

b) Agar perawat dapat melakukan tugasnya dengan baik dalam pengisian dokumen standar asuhan keperawatan.

\section{DAFTAR PUSTAKA}

1. Depkes, RI, Rumah Sakit Tahun 2009: http//www.depkes.go.id, diakses tanggal 6 Juni 2010, Yogyakarta, 2009

2. Azwar, A., Pengantar Administrasi Kesehatan, Edisi Revisi, Binarupa Aksara, Jakarta, 2010

3. Aditama, T.Y., Manajemen Administrasi Rumah Sakit, Universitas Indonesia (UIPress), Jakarta, 2003

4. Nurachmah, E., Asuhan Keperawatan Bermutu di Rumah Sakit, di Sajikan pada Seminar Keperawatan RS Islam Cempaka Putih, diakses tanggal 20 April 2010, Jakarta, 2001

5. Depkes, RI., Rencana Strategi Kementerian Kesehatan Tahun 2010-2014: http// www.depkes.go.id, diakses Tanggal 6 Juni 2010, Yogyakarta, 2010

6. Arikunto, S., Prosedur Penelitian Suatu Pendekatan Praktek, PT Rineka Cipta, Jakarta, 2002 